\title{
CONTINUUMCATEGORIAL ENTRE EXPLICAÇÃO E RESTRIÇÃO: UMA ANÁLISE DE ORAÇÕES RELATIVAS
}

\section{CATEGORICAL CONTINUUM BETWEEN NON-RESTRICTION AND RESTRICTION: AN ANALYSIS OF RELATIVE CLAUSES}

\author{
Edvaldo Balduíno Bispo (UFRN) ${ }^{1}$ \\ Anielle Bruna Fonseca Lopes (SEEC/RN) ${ }^{2}$
}

\section{RESUMO}

Neste artigo, analisamos orações relativas à luz de um continuum categorial entre a explicação e a restrição. Objetivamos identificar propriedades formais e semântico-pragmáticas dos SN antecedentes e correlacioná-las ao tipo de relativa a eles vinculado, elucidando, assim, que aspectos do antecedente motivam o uso de restritivas ou de explicativas e qual a contribuição discursivo-pragmática dessas orações para a cláusula matriz e para o texto de que fazem parte. A pesquisa tem abordagem quali-quantitativa e caráter descritivo-explicativo; sustenta-se teoricamente na vertente norte-americana da Linguística Funcional (GIVÓN, 1995; MARTELOTTA, 2011; FURTADO DA CUNHA; BISPO, 2013) e na proposta de Oliveira (2001) para a integração das relativas à oração matriz. Os resultados indicam que orações restritivas ocorrem em maior quantidade com antecedentes novos e menos definidos, enquanto as explicativas, mais frequentemente, ligam-se a SN disponíveis e com maior grau de definitude. Antecedentes evocados e inferíveis ocorrem com ambos os tipos de relativas, assim como aqueles com grau intermediário de definitude. Esses achados revelam que esses dois grupos de relativas não representam categorias discretas, mas abarcam um conjunto de orações que se distribuem numa escala categorial em cujos extremos situam-se as explicativas típicas, com menor grau de integração à oração matriz e a ela relacionadas por adjunção/hipotaxe, e as restritivas prototípicas, com maior aderência morfossintática à matriz e a ela articuladas por encaixamento/subordinação.

PALAVRAS-CHAVE: Orações relativas. Continuum categorial. Linguística Funcional.

\section{ABSTRACT}

In this paper, we analyze relative clauses considering a categorical continum between nonrestriction and restriction. We aim to identify formal and semantic-pragmatic properties of the head nouns and to correlate them to the type of relative clause linked to them, by revealing which aspects from the head noun motivate the usage of restrictive or non-restrictive relative clauses and which discourse-pragmatic contributions these relative clauses gives to the main clause. It is a qualitative and quantitative research and it has descriptive and explanatory objectives. The theoretical support is the North-American Functional Linguistics (GIVÓN, 1995; MARTELOTTA, 2011; FURTADO DA CUNHA; BISPO, 2013) and the proposal of Oliveira (2001) to the integration between main and relative clauses. The results show that restrictive clauses occur in greater quantity with new and less defined head nouns, while non-restrictive clauses, more frequently, are linked to available head nouns with a greater degree of definiteness.

\footnotetext{
${ }^{1}$ Doutor em Estudos da Linguagem pela UFRN. Professor Associado do Departamento de Letras e do Programa de Pós-graduação em Estudos da Linguagem (PPgEL/UFRN). E-mail: edvaldo.bispo@ufrn.br.

${ }^{2}$ Mestra em Estudos da Linguagem pela UFRN. Professora de Língua Portuguesa da Rede Estadual e Ensino do Rio Grande do Norte. E-mail: anibruna1695@hotmail.com.
} 
Evoked and inferable head nouns appear with both types of relative clauses, as well as those with an intermediate degree of definiteness. These findings reveal that these two groups of relative clauses do not represent discrete categories, but encompass a set of clauses that are distributed on a categorical scale at the ends of which are the typical non-restrictive clauses, with a lower degree of integration to the matrix clause and related to it by hypotaxis, and the prototypical restrictive ones, with greater morphosyntactic adherence to the matrix clause and articulated to it by embedding/ subordination.

KEY-WORDS: Relative clauses. Categorical conitnumm. Functional Linguistics.

\section{INTRODUÇÃO}

As orações relativas constituem campo fértil de investigação e têm despertado o interesse de muitos estudiosos de diferentes afiliações teóricas, como gerativistas e funcionalistas de distintos matizes, sociolinguistas e construcionistas. Também têm sido considerados variados aspectos desse tipo oracional: configuração estrutural, estratégias de relativização, tipologia, processos de variação e mudança, pareamento forma-função e questões atinentes a ensino de língua, entre outros.

Para uma breve ilustração, podemos citar os trabalhos de Mollica (1977) e de Tarallo (1983), que dão conta das estratégias de relativização; os de Correa (1998) e Varejão (2006), discutindo a variação no uso das relativas; os de Brito (1988), Kenedy (2007) e Marchesan (2012), dedicados a descrever e a analisar formalmente esse tipo oracional; as pesquisas de Souza (2009), Bispo (2009, 2014a), Decat (2011), Bispo e Braga (2021), voltadas a aspectos funcionais no uso dessas cláusulas; as investigações de Bispo (2007), Leitão (2009), Amorim (2011), Câmara (2015), Silva (2020), que contemplam descrição formal-funcional e questões atinentes ao ensino das relativas; as de Bispo e Amurim (2019) e Bispo e Silva (2020), dedicadas à abordagem dessas orações em turmas da Educação Básica; os estudos de Tarallo (1983), Bispo (2014b) e Silva (2011), que as investigaram sob um olhar diacrônico; os de Perroni (2001) e Codinhoto (2016), acerca da aquisição das relativas; ou ainda os trabalhos de Bispo $(2018,2020)$, com um viés funcional-construcionista sobre o fenômeno em tela.

Por essa lista, não exaustiva, podemos perceber o quão amplo é o leque de possibilidades de abordagem das orações relativas. A discussão aqui empreendida dialoga mais estreitamente com os estudos de Oliveira (2001), Souza (2009) e Leitão (2009). Oliveira trata da distinção entre restritivas (1a) e explicativas (1b) como um contínuo, considerando o nível de integração entre o antecedente e a relativa e entre esta e a oração matriz. Souza (2009) investiga o grau de integração fonética entre relativas e antecedentes e a relação entre algumas propriedades do antecedente, como o grau de definitude e o tipo de relativa. Embora repliquemos, em parte, parâmetros presentes em Oliveira e em Souza, nenhuma das duas autoras correlaciona o status informacional do antecedente ao tipo de oração relativa como aqui fazemos, mostrando tendências quantitativas com base no cruzamento entre restritivas e explicativas e propriedades do antecedente.

(1) No fim de semana, o dia mais violento foi o sábado (29), com 12 mortes, enquanto sexta (28) e domingo (30) tiveram seis homicídios, cada um. O local (1a) em que ocorreram mais crimes foi Ceará-Mirim, (1b) onde sete pessoas foram mortas. (Tribuna do Norte, 31/07/2017)

Neste artigo, em particular, focalizamos as relações de restrição e explicação, associadas a essas orações em uma perspectiva escalar. Consideramos, para tanto, aspectos morfossintáticos e semântico-pragmáticos do Sintagma Nominal (SN) antecedente e da oração relativa. Objetivamos identificar propriedades formais e semântico-pragmáticas dos SN antecedentes e correlacioná-las 
ao tipo de relativa a eles vinculado, elucidando, assim, que aspectos do antecedente motivam o uso de restritivas ou de explicativas e qual a contribuição discursivo-pragmática dessas orações para a cláusula matriz e para o texto de que fazem parte. Em termos específicos, pretendemos: i) identificar propriedades estruturais, semânticas e discursivo-pragmáticas dos antecedentes das relativas do corpus analisado; ii) correlacionar essas propriedades do antecedente à classificação das relativas; iii) organizar as orações analisadas num continuum de integração semântico-sintática entre relativa e $\mathrm{SN}$ antecedente, colocando em um extremo as mais integradas ao antecedente e, em outro, as menos integradas; iv) identificar a função das relativas restritivas e das explicativas em termos semânticos e/ou discursivo-pragmáticos.

Fundamentamos nossa investigação na vertente norte-americana do Funcionalismo Linguístico, conforme caracterizamos na próxima seção. Utilizamos como fonte empírica ocorrências retiradas de notícias e reportagens extraídas de 25 edições impressas do jornal potiguar Tribuna do Norte, datadas de maio a julho de 2017.

O artigo compõe-se de cinco seções, além da introdução. $\mathrm{Na}$ primeira delas, caracterizamos a perspectiva teórica em que fundamentamos nossa discussão. $\mathrm{Na}$ seção 2, apresentamos a metodologia do trabalho. Nas seções seguintes, explicitamos e analisamos os dados obtidos em nosso levantamento: na terceira, tratamos das propriedades semânticopragmáticas dos SN antecedentes e as correlacionamos ao tipo de relativa a eles vinculado; na seção 4, discutimos a integração da relativa à oração matriz, em termos escalares, à luz de parâmetros semântico-sintáticos. A última seção é dedicada às considerações finais.

\section{Lastro teórico}

O estudo aqui reportado sustenta-se teoricamente na Linguística Funcional norteamericana, inspirada em Talmy Givón, Sandra Thompson, Paul Hopper, para citar alguns. Givón (1995) aponta um conjunto de premissas amplamente aceitas no meio funcionalista, dentre as quais o postulado de que a estrutura linguística é não-arbitrária, motivada e icônica. De fato, uma das ideias centrais da abordagem funcionalista é a de que as estruturas das línguas são fortemente determinadas por suas funções (semântico-cognitivas e discursivo-pragmáticas), conforme nos lembram, entre outros, Martelotta (2011) e Furtado da Cunha e Bispo (2013). Nessa direção, a língua é tomada como uma estrutura fluida, maleável, um sistema adaptativo complexo (DU BOIS, 1985; BYBEE, 2016 [2010]), suscetível a demandas de ordem cognitiva e comunicativa. A gramática de uma língua natural, por sua vez, constitui um conjunto de padrões regulares, decorrentes de rotinas linguísticas consensuadas, ao lado de formas alternativas em processo de mudança, motivada por fatores cognitivos, culturais e interacionais.

Assim sendo, uma investigação sob esse viés teórico tem, necessariamente, de considerar usos linguísticos efetivos em seu lócus de realização, de forma a explicitar os fatores internos e, sobretudo, externos à língua que contingenciam tais usos.

Para este estudo, levamos em consideração os seguintes conceitos operacionais tomados como categorias analíticas: informatividade, com base em Chafe (1979) e Prince (1981); integração oracional, conforme cline proposto por Hopper e Traugott (1993) e segundo discutido em Oliveira (2001); especificidade do SN, com base em Chafe (1979) e no contínuo proposto por Souza (2009).

O conceito de informatividade está relacionado ao conteúdo informacional que os interlocutores compartilham, ou supõem compartilhar, no momento da interação verbal. Nos termos de Prince (1981), trata-se de uma "familiaridade assumida" pelos participantes do ato comunicativo. Em função desse conhecimento (supostamente) partilhado, ou assumidamente familiar, o falante não só procura gerenciar o conteúdo informacional para seu interlocutor mas também se esforça em monitorar/orientar o ponto de vista deste, com o fim de alcançar determinado(s) objetivo(s). 
Os estudos clássicos sobre informatividade voltam-se ao estatuto informacional de referentes nominais, classificando-os em novo, evocado (dado ou velho), inferivel e disponivel. Assim, quando não está ativo na memória do interlocutor, seja por não ter sido mencionado no discurso ou por não estar acessível na situação comunicativa, um referente constitui informação nova, sendo codificado, por exemplo, por um SN lexical (um estudante de engenharia; um homem, no trecho em (2)). Quando tiver sido apresentado ou estiver acessível no contexto de interação, representa informação evocada (dada/velha), como é o caso do referente de a dupla, no fragmento a seguir, daí a codificação por $\mathrm{SN}$ com artigo definido ${ }^{3}$. O inferível é aquele identificado por dedução com base em pistas linguísticas, conforme se dá com a polícia (= aqueles que efetuaram a prisão dos suspeitos de tráfico de drogas). Por fim, é disponível o referente amplamente conhecido, geralmente único, ao qual os interlocutores facilmente têm acesso, como acontece com Angra dos Reis (cidade litorânea do Rio de Janeiro).

(2) Um estudante de engenharia, de 26 anos, e um homem, de 25, foram presos por suspeita de tráfico de drogas sintéticas, na Costa Verde do Rio. Segundo a polícia, a dupla estava com 182 gramas de haxixe, 22 comprimidos de ecstasy, uma quantidade de MDMA (variação do ecstasy com alto poder alucinógeno) e LSD.

As prisões aconteceram na cidade de Mangaratiba, nesta terça-feira. Segundo o delegado Vilson de Almeida Silva, da 166ªP (Angra dos Reis), já se sabe que a maior parte do material apreendido seria vendido em uma festa rave, marcada para acontecer no dia 6 de fevereiro, em Angra dos Reis. (NUNES, 2021).

No que diz respeito à integração de cláusulas, recorremos a Hopper e Traugott (1993), que desenvolveram um cline com níveis de integração oracional, acrescentando uma categoria entre a coordenação e a subordinação: a hipotaxe. A proposta dos autores assenta-se no postulado givoniano de que as formas da língua se originam de maneira mais solta, ou paratática, e passam por mudanças linguísticas até se tornarem mais integradas (GIVÓN, 2012 [1979]). A Figura 1 sintetiza o cline com as três categorias propostas e as características de cada uma delas.

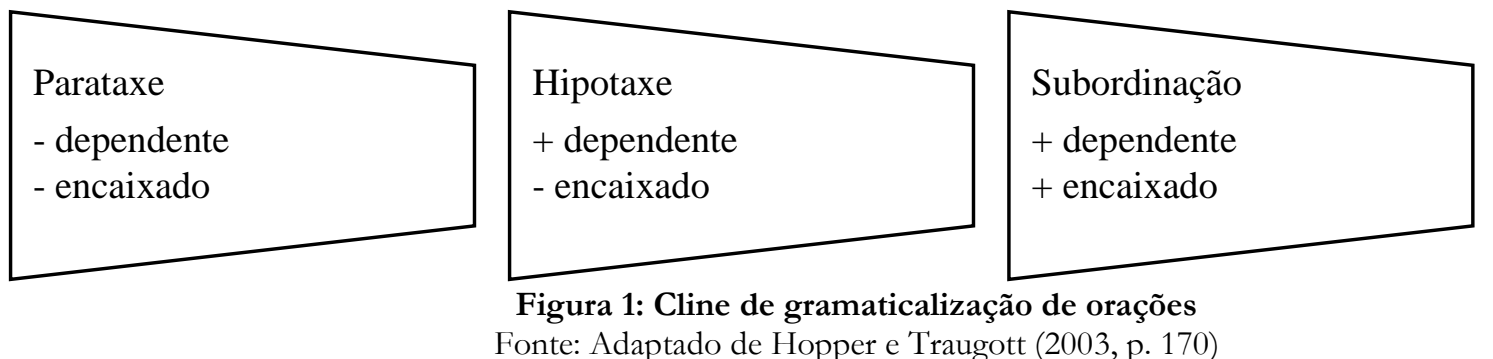

A parataxe caracteriza-se pela relativa autonomia semântica e equivalência sintática entre as orações que se articulam (RODRIGUES, 2010). As orações paratáticas apresentam núcleos independentes sintaticamente, que se relacionam entre si por meio de inferências semânticas. É o caso das orações destacadas em (3), que possuem o mesmo estatuto gramatical, sendo hierarquicamente equivalentes. Entre elas estabelece-se relação explicativa.

(3) O governador Robinson Faria considerou o momento como de grande importância econômica e social. "A administração estadual assume a sua gestão e isso significa uma grande oportunidade econômica para o Rio Grande do Norte, porque vai gerar

\footnotetext{
${ }^{3}$ Cabe registrar que o referente pode ser contextualmente evocado (já mencionado no texto) ou situacionalmente evocado (disponível no entorno da situação comunicativa).
} 
empregos, renda e arrecadação ao poder público", afirmou. (Tribuna do Norte, 02/08/2017)

A hipotaxe se refere ao tipo de combinação em que a uma oração matriz se conecta uma oração "margem", "satélite", a qual é constituinte daquela. Trata-se de uma relação núcleodependente por adjunção circunstancial. Ilustram esse tipo de articulação as orações destacadas em (4): a primeira delas veicula circunstância temporal em relação ao conteúdo da oração matriz (sublinhada no trecho) e entre ambas há uma relação hierárquica satélite-núcleo, nessa ordem.

(4) A escola estava perto de três bocas de fumo, e os traficantes tentavam vender drogas para os alunos durante os intervalos de aula. Quando os professores começaram a tentar impedir, foram ameaçados e os saques começaram”, disse a secretária. (Tribuna do Norte, 28/06/2017)

Ocorre subordinação quando há maior dependência semântico-sintática de uma oração em relação a outra. Nesse caso, dá-se encaixamento de uma oração (a subordinada) na oração matriz. É o que podemos observar entre as cláusulas que constituem o período destacado em (5): a segunda encaixa-se no verbo da primeira (estimar), servindo-lhe de complemento (objeto direto), ou seja, trata-se de um constituinte da oração matriz; semanticamente, veicula o conteúdo do que é estimado.

(5) A maioria de espécies de tubarão de mar aberto podem ser extintas Pesquisadores estimam que as populações de tubarões e raias diminuíram $\mathbf{7 1 \%}$ nas últimas cinco décadas. O motivo? Pesca desenfreada. (FIORATTI, 2021)

Acompanhando Oliveira (2001), Souza (2009), Castilho (2010), Rodrigues (2010), entre outros, defendemos que as orações relativas se situam entre a hipotaxe e a subordinação, conforme discutimos na seção 4.

Oliveira (2001), ao propor um contínuo entre relativas restritivas e relativas explicativas, vale-se de quatro critérios semântico-sintáticos para aferir o grau de integração oracional. São eles: informatividade do SN, fundidade da relativa, pausa e inserção.

Segundo a autora, a informatividade do SN diz respeito a seu grau de definição/especificação ou de caracterização ${ }^{4}$. Elementos menos definidos, mais genéricos ${ }^{5}$ e abstratos têm baixo grau de informatividade e a ele se ligam orações relativas com mais peso semântico para o recorte de seu referente, ou seja, as de valor restritivo.

O conceito de fundidade está relacionado à menor relevância do conteúdo da oração relativa. Nos casos de aposição ou explicação, por exemplo, a informação da relativa é secundária, justamente porque o grau de informatividade do elemento nominal a que ela se liga é maior. Desse modo, esse critério liga-se intimamente ao anterior numa relação diretamente proporcional: quanto maior a informatividade do SN antecedente, maior a fundidade da oração relativa.

A pausa constitui uma quebra de unidade no encaixamento de orações, já que, de acordo com o princípio da proximidade, quanto mais unidos estiverem dois termos no plano conceitual, mais próximos estarão na ordem linear da expressão linguística (GIVÓN, 1984). Assim, a

\footnotetext{
4 Oliveira (2001) considera SN específicos aqueles marcados por artigos definidos, expressões no singular acompanhadas de numerais, dêiticos ou atributos e nomes próprios. Já os nomes menos específicos correspondem aos abstratos, genéricos, acompanhados de artigos ou pronomes indefinidos, no plural e desacompanhados de maior determinação.

${ }^{5}$ Chafe (1979, p. 192) define genericidade como "a totalidade de uma substância ou classe frente a um exemplo da substância ou um membro da classe”. Em outras palavras, genérica é toda unidade que corresponde à totalidade de uma classe ou substância (ex.: Criança dá trabalho).
} 
ocorrência de pausa entre a relativa e a oração matriz implica menor grau de vinculação entre elas, enquanto a ausência de pausa promove o oposto.

Por fim, a variável inserção também se refere à questão da proximidade e consiste na inclusão de elemento(s) entre a oração matriz e o pronome relativo ou entre este e o restante da cláusula relativa. Quando essa variável ocorre, reduz-se ou quebra-se o vínculo entre os elementos distanciados. Consideremos as orações destacadas em (6) e (7), analisadas à luz desses critérios:

(6) "Vale mais a pena tentar vender a alguém que aceite levar adiante a produção, investir um pouco mais, tentar revitalizar, do que fechar, gastar e devolver para a ANP (Agência Nacional de Petróleo, Gás Natural e Biocombustíveis) sem ganhar um tostão", diz Prates, ressaltando que "fechar" geraria custos porque seria preciso deixar tudo como estava antes de a empresa entrar. (Tribuna do Norte, 29/07/2017)

(7) Nesta quarta-feira (28), a Câmara de Natal aprovou em segunda discussão o Projeto de Lei $\mathrm{n}^{\circ}$ 40/2017, de autoria do presidente da Casa, vereador Raniere Barbosa (PDT), que cria a Lei Karol Álvares, instituindo o dia 20 de janeiro como o Dia Municipal das Mães que sofrem da Síndrome dos Braços Vazios, em razão da violência urbana. A iniciativa recebeu parecer favorável de todos os parlamentares presentes no plenário. (Tribuna do Norte, 29/06/2017)

Em (6), temos um caso de relativa com maior integração semântico-sintática à oração matriz: SN antecedente (alguém) de caráter genérico, indefinido; conteúdo da relativa altamente relevante para o recorte referencial do antecedente; ausência de pausa e de inserção. A relativa em (7), de valor explicativo, apresenta menor vinculação de forma e conteúdo: SN antecedente bem recortado (inclusive com especificação numérica), daí o caráter de fundo da relativa; presença de pausa, marcada, na escrita, pelo uso de sinal de pontuação; e inserção de material interveniente (a expressão apositiva que indica a autoria do projeto), distanciando antecedente (Projeto de Lei $\mathrm{n}^{\circ}$ 40/2017) e pronome relativo.

Souza (2009), com base na discussão de Chafe (1979) acerca das propriedades de definitude e genericidade atribuídas a SN, propõe um tratamento escalar para aferição da especificidade/definitude dos referentes nominais. A pesquisadora correlaciona o "grau de definitude" do SN à sua constituição morfossintática. No Quadro 1, resumimos a proposta da autora:

\begin{tabular}{|c|c|}
\hline Máximo & [N próprio]; [N comum] + [SP com N próprio]; [Pro pessoal] \\
\hline Alto & {$[$ Poss + N]; [Dem + N]; [Dem + N + SA $] ;[$ Dem + N + SA + SP $]$} \\
\hline Médio & $\begin{array}{l}{[(\text { Art Def })+\mathrm{N}+\mathrm{SP}] ;[\text { (Art Def) }+\mathrm{N}+\mathrm{SA}] ;[(\text { Art Ind })+\mathrm{N}+\mathrm{SP}] ;[\text { (Art Ind })+} \\
\mathrm{N}+\mathrm{SA}]\end{array}$ \\
\hline Baixo & $\begin{array}{l}{[(\text { Art Def })+N] ;[(\text { Art Ind })+N] ;[(\text { Quant })+N] ;[\text { Quant }+ \text { Art Def }+N] ;[\text { Ind + }} \\
N]\end{array}$ \\
\hline Mínimo & [Ind]; [Dem]; [(Art Def) + N genérico]; [(Art Ind) + N genérico] \\
\hline
\end{tabular}

A autora esclarece que a ordem dos constituintes não é necessariamente a que sugerem os esquemas do quadro, ou seja, há flexibilidade da posição de alguns elementos em relação ao núcleo, como os adjetivos, por exemplo. Além do mais, a ocorrência de SA e SP pode se replicar diversas vezes dentro do SN. Por fim, os parênteses indicam que alguns constituintes podem ou não ocorrer. 
Em nossa análise, consideramos, além da proposta de escalaridade de Souza (2009) e da noção de informatividade do SN discutida em Oliveira (2001), a definição de genericidade de Chafe (1979).

\section{Aspectos metodológicos}

Para o empreendimento deste estudo, valemo-nos tanto do raciocínio indutivo quanto do dedutivo, o que caracteriza, conforme Givón (1995), o método abdutivo de análise. O viés indutivo reside na consideração de instâncias particulares do fenômeno sob investigação para, a partir delas, chegar a determinadas generalizações. O caráter dedutivo decorre da ancoragem em uma base teórica consolidada, com postulados e premissas consistentes e fortemente referendadas na empiria.

Quanto à abordagem do fenômeno, a pesquisa é eminentemente qualitativa, com suporte quantitativo. Em termos de objetivos, caracteriza-se como descritivo-explicativa (SILVA, 2004; LAKATOS; MARCONI, 2010). A natureza qualitativa da pesquisa diz respeito ao caráter descritivo e explicativo/interpretativista do trabalho, no sentido de explicitar e correlacionar propriedades formais, semânticas e pragmáticas dos SN antecedentes e das relativas a eles vinculadas. $\mathrm{O}$ viés descritivo-quantitativo está relacionado à caracterização do objeto de estudo em termos de mensuração das ocorrências e de sua distribuição quanto aos fatores estruturais (configuração morfossintática), semânticos (definitude/ genericidade, restrição/comentário) e pragmáticos (estatuto informacional, objetivo comunicativo: precisão referencial, justificativa, argumentação etc.).

O banco de dados tomado por amostra é composto por 25 notícias e reportagens extraídas de 25 edições impressas do jornal potiguar Tribuna do Norte, presentes na coluna Natal, datadas de maio a julho de 2017. A dimensão de cada texto comporta uma variação de 344 a 652 palavras. A opção por notícias e reportagens se deveu ao fato de esses gêneros textuais ${ }^{6}$ possuírem grande alcance, de sua redação representar tendências da escrita corrente e de trazer assunto da atualidade, sendo, por essas razões, um bom exemplo de língua em uso.

Uma vez que este trabalho destaca a relação entre SN antecedente e oração relativa, foi necessário delimitar o universo das orações consideradas. Ocupamo-nos das relativas desenvolvidas que possuem um referente explícito. Assim, na identificação das ocorrências, não foram levadas em conta aquelas sem antecedente lexicalmente rastreável, as que não possuem pronomes relativos (como as reduzidas), as relativas que se encontram em frase distinta do antecedente, tratadas como 'desgarradas' por Decat (1999, 2011).

Feito o levantamento de todas as relativas do corpus, os dados foram tabulados conforme os fatores de análise. Desse modo, há tabelas com informações quantitativas referentes aos graus de definitude do SN e a seu estatuto informacional e aos parâmetros de integração oracional. Em nossa análise, cruzamos os critérios atinentes ao SN antecedente com a classificação das relativas em restritivas e explicativas.

\section{Propriedades do SN antecedente e tipologia semântica das relativas}

Nesta seção, tratamos de duas propriedades do SN antecedente que possuem estreita relação entre si: o status informacional e o grau de definitude. Isso porque referentes evocados geralmente se apresentam recortados semanticamente e tendem a ser codificados por SN definidos, pronomes e anáfora zero, ao passo que referentes novos, via de regra, remetem a

\footnotetext{
${ }^{6}$ Entendemos, com base em Marcuschi $(2005,2008)$, que os gêneros textuais e as sequências textuais em elaboração selecionam determinados recursos léxico-gramaticais para sua composição estrutural.
} 
entidades mais genéricas, codificadas por nomes frequentemente antecedidos por artigos ou pronomes indefinidos, por consequência de seu status informacional (GORSKI, 1985).

Prince (1981) lembra que, conquanto haja proximidade entre tais categorias, elas não são equivalentes, o que justifica abordá-las de forma separada. Entendemos, contudo, que propriedades relativas ao status informacional do SN antecedente certamente reverberam em características da definitude desse mesmo antecedente.

Quanto à correlação entre tipo semântico da relativa e estatuto informacional do SN antecedente, examinamos em que medida se confirma em nosso corpus a hipótese de que restritivas se vinculam mais a SN novos do que as explicativas, baseando-nos em Oliveira (2001), Souza (2009) e Leitão (2009). Assim, cruzando as ocorrências de restritivas e de explicativas com o estatuto informacional do SN antecedente dessas orações, obtivemos os resultados sintetizados na Tabela 1.

\begin{tabular}{|c|c|c|c|c|c|c|c|c|c|c|}
\hline \multirow{3}{*}{$\begin{array}{l}\text { Tipologia da } \\
\text { relativa }\end{array}$} & \multicolumn{8}{|c|}{ Status informacional do SN antecedente } & \multicolumn{2}{|c|}{ Total } \\
\hline & \multicolumn{2}{|c|}{ Disponível } & \multicolumn{2}{|c|}{ Evocado } & \multicolumn{2}{|c|}{ Inferível } & \multicolumn{2}{|c|}{ Novo } & \multirow[b]{2}{*}{$\mathrm{N}^{\mathrm{o}}$} & \multirow[b]{2}{*}{$\%$} \\
\hline & $\mathrm{N}^{\mathrm{o}}$ & $\%$ & $\mathrm{~N}^{\circ}$ & $\%$ & $\mathrm{~N}^{\mathrm{o}}$ & $\%$ & $\mathrm{~N}^{\mathrm{o}}$ & $\%$ & & \\
\hline Explicativa & 22 & $30,1 \%$ & 36 & $49,3 \%$ & 12 & $16,4 \%$ & 3 & $4,1 \%$ & 73 & $100 \%$ \\
\hline Restritiva & 0 & $0 \%$ & 40 & $40,8 \%$ & 14 & $14,3 \%$ & 44 & $44,9 \%$ & 98 & $100 \%$ \\
\hline
\end{tabular}

Tabela 1: Relação entre tipo de relativa e status informacional do SN antecedente Fonte: Adaptado de Lopes (2019, p. 77)

Os quantitativos dão conta de que as orações explicativas se associam, preferencialmente, a antecedentes disponíveis e evocados, os quais, juntos, equivalem a quase $80 \%$ dos casos de explicativas encontradas no corpus. Apenas 4\% dessas orações vinculam-se a SN novos no discurso. Esse baixo percentual se deve à própria natureza desse tipo oracional. Vejamos as amostras em (8) e (9):

(8) Para o analista, a possível entrada de novos investidores poderá representar a retomada do crescimento da produção, "pelo menos por alguns anos", "algum investimento em tecnologia, alguma revitalização local em termos de empregos e investimentos diretos na região, mas não é de se esperar grandes descobertas que mudem o rumo desses campos, que já vêm em meio a uma história de decadência". (Tribuna do Norte, 29/07/2017)

(9) A Petrobras é operadora de todas as concessões, com 100\% de participação, exceto nas de Pescada e Arabaiana, com uma fatia de 65\%, em cada. Os outros 35\% estão com a Ouro Preto Óleo e Gás, que tem à frente Rodolfo Landim, ex-presidente da OGX Petróleo e Gás, de Eike Batista. (Tribuna do Norte, 29/07/2017)

As relativas destacadas em (8) e (9) estão ligadas a SN cujos referentes são conhecidos. $\mathrm{Em}$ (8), o referente do SN antecedente (esses campos) representa uma entidade evocada, posto que já vinha sendo mencionada desde o início do texto, o qual tem como tema principal a venda de áreas de petróleo no RN. Esse estatuto de entidade evocada também é evidenciado pelo uso do demonstrativo esses, que possui valor anafórico. O conteúdo da oração explicativa funciona como comentário acerca do SN antecedente, mas com informação relevante para o assunto tratado na reportagem: que os campos de petróleo alvo do pacote de vendas estavam em situação de decadência. Parece, portanto, servir como uma espécie de justificativa para os planos da 
Petrobras em privatizá-los. Vemos, assim, a motivação pragmático-discursiva da relativa explicativa, conforme tratado em Leitão (2009).

Quanto ao SN ao qual a relativa em (9) está vinculada (Ouro Preto Óleo e Gás), seu referente é disponível, pois remete a entidade única (trata-se de empresa específica), contexto em que a restritiva não ocorre devido à alta definitude do antecedente. Novamente, a relativa explicativa traz um comentário sobre o SN antecedente, também com valor pragmático: explicitar relação da Ouro Preto Óleo e Gás com a empresa de Eike Batista, empreiteiro que mantinha altos negócios no ramo petrolífero com o Governo Federal e alvo de investigações sobre corrupção na Petrobras.

No que diz respeito às relativas restritivas, conforme mostram os números da Tabela 1 , há maior incidência desse tipo oracional vinculado a $\mathrm{SN}$ que representam entidades novas, com $45 \%$ do total de restritivas, a exemplo de (10). Cabe destacar, porém, que ocorreram $40 \%$ de orações restritivas acompanhando SN já evocados no discurso, caso ilustrado em (11), o que nos parece uma contraexpectativa, considerando o papel de recorte semântico associado a essas orações. Contudo, entendemos que esse significativo percentual de restritivas vinculadas a referentes evocados se dá porque o fato de um antecedente ter sido evocado não implica dizer que seu significado esteja delimitado o bastante, pois ocorrem situações em que existe mais de um referente possível no texto, e a restritiva contribui para identificar de qual deles se trata, conforme acontece em nossos dados. A amostra (12) ilustra essa situação.

(10) Considerando que o direito ao lazer se configura como um direito social, tem-se que devida a adoção de medidas que assegurem que as diferenças porventura identificadas em referidas categorias não passem de meros detalhes ${ }^{7}$, destituídas do poder de comprometer a sua livre fruição. (Tribuna do Norte, 28/06/2017)

(11) Um ano depois de ter sido alvo de saques e depredações por parte de vândalos, a Escola Municipal Limírio Cardoso Dávila, localizada no bairro de Bela Vista, em Parnamirim, permanece em ruínas. Com mato crescendo ao redor do terreno; um carro abandonado e destruído em um dos cantos, e a entrada onde ficava o portão bloqueada por um muro, nada, além de uma quadra, indica que o local, pouco tempo atrás, era um espaço de ensino e aprendizado para cerca de $\mathbf{6 0 0}$ alunos que cursavam o Ensino Fundamental. (Tribuna do Norte, 28/06/2017)

(12) Diante deste cenário, duas matérias apresentadas pelo vereador Aldo Clemente (PMB) que abordam a temática receberam parecer favorável do plenário. Uma que institui a "Semana Municipal de Educação, Conscientização e Orientação sobre a Fissura Labiopalatina"; outra que reconhece a Associação de Pais e Amigos dos Fissurados do Rio Grande do Norte - APAFIS como entidade de utilidade pública. (Tribuna do Norte, 30/06/2017)

A oração sublinhada em (10) está ligada ao SN medidas, que não foi mencionado no discurso nem é inferível, designando, pois, uma entidade nova. A relativa destacada contribui para o recorte referencial desse elemento, especificando-o para o leitor. Assim, a oração restritiva compensa o fato de o antecedente não ser conhecido ou previsível nesse ponto do discurso, facilitando sua referência. Em (11), contudo, alunos codifica uma informação inferível, pois, no contexto de uma escola, essa entidade é facilmente ativada pelos interlocutores. Apesar disso, nesse contexto em específico, a referência é um pouco genérica, pois, além de tratar apenas de uma quantidade aproximada do número de alunos, o SN 600 alunos designa ampla coletividade, referente não individualizado. Nesse caso, o repórter pode ter restringido essa expressão nominal com o propósito de esclarecer que não se tratava de alunos do ensino médio ou infantil, mas do

\footnotetext{
${ }^{7}$ A inclusão do trecho "que as diferenças porventura identificadas em referidas categorias não passem de meros detalhes" deve-se ao fato de ele funcionar como objeto direto do verbo da oração relativa (assegurar).
} 
fundamental. Isso traz ao leitor a informação de que se trata de uma escola de nível fundamental, em oposição a escola(s) de outro(s) nível(is), o que não havia sido dito anteriormente no texto. Do ponto de vista discursivo-pragmático, o fato de se tratar de um grupo de alunos mais jovens diante de um ambiente dominado pelo tráfico enfatiza o quão degradante é a situação.

No caso de (12), as duas orações em destaque restringem o significado de matéria, SN já conhecido pelos interlocutores, dado que apareceu no primeiro período, daí sua elisão no período em que se encontram as relativas restritivas. Visto que há duas matérias em questão, as relativas são usadas para se referir a cada uma delas de forma individualizada.

Em nossos dados, verificamos a ocorrência da oração restritiva associada a antecedente novo, inferível e evocado no discurso. Esse tipo de relativa só não ocorreu vinculada a $\mathrm{SN}$ que remetem a entidades disponíveis, devido à referência única desses SN.

Em suma, comparando os dados das restritivas com os das explicativas, constatamos que os $\mathrm{SN}$ novos ocorrem com mais frequência com orações restritivas, o que confirma nossa hipótese. Os evocados ocorrem com ambos os tipos de relativas, com motivações discursivopragmáticas distintas, ao passo que os SN disponíveis, de maneira geral, são ancorados apenas por orações explicativas. Quanto aos inferíveis, não há distinções relevantes nos percentuais aferidos.

Em termos de grau de definitude do SN antecedente, consideramos a correlação entre esse fator, com base em Souza (2009), e o tipo semântico da relativa. A análise das ocorrências permitiu-se chegar aos resultados sumarizados, quantitativamente, na Tabela 2.

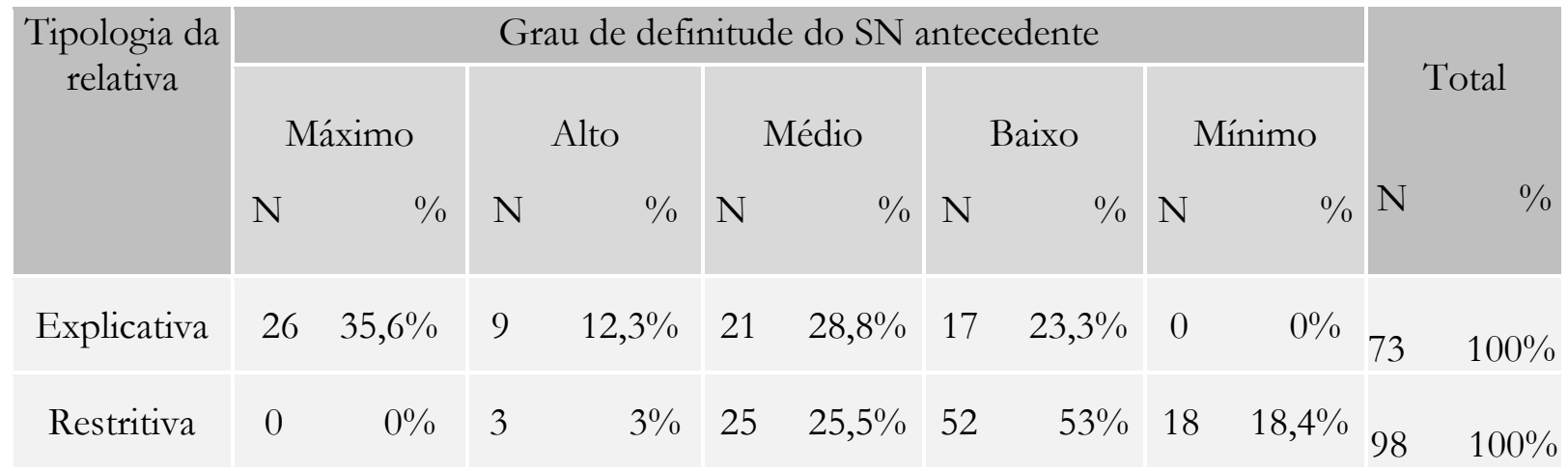

Tabela 2: Relação entre tipo de relativa e grau de definitude do SN antecedente Fonte: Adaptado de Lopes (2019, p. 82)

Conforme mostram os números da Tabela 2, as orações explicativas ocorreram mais frequentemente vinculadas a SN com graus máximo $(35,6 \%)$ e médio $(28,8 \%)$ de especificidade. Destacamos que o somatório dos graus mais elevados de definitude (alto e máximo), ilustrados, respectivamente, em (13) e (14), respondem por $48 \%$ dos $\mathrm{SN}$ a que se ligam essas relativas: configurações Dem $+\mathrm{N}+\mathrm{SP}$ (esse trabalho do TCE) e N próprio (Correia). As orações restritivas, por sua vez, não apareceram com SN de grau máximo de definitude e apenas em 3\% com nomes de grau alto. A maioria das restritivas do corpus $(71,4 \%)$ vinculam-se a $\mathrm{SN}$ com graus baixo e mínimo de especificidade, ilustrados em (15) e (16), com os formatos Art Def $+\mathrm{N}$ (o esquema) e $\mathrm{N}$ genérico (tudo), respectivamente.

(13) Das 313 obras, as paralisadas em 58\%, com investimentos de $\mathrm{R} \$ 268$ milhões (87\%) e as inacabadas $42 \%$, onde foram investidos V 40, 28 milhões (13\%). As maiores causas são atrasos ou suspensão dos repasses financeiros da União (40,3\%) ou por distrato ou abandono das obras pelas construtoras (15,7\%), segundo esse trabalho do TCE, que vem sendo realizado desde 2015. (Tribuna do Norte, 24/06/2017)

(14) "Estamos com a Divisão de Homicídios e Proteção a Pessoa (DHPP) reforçada, com mais viaturas e policiais. Remanejamos policiais de outras unidades dentro do estudo 
de mancha criminal, onde há maior necessidade de investigação, para darmos maior andamento aos trabalhos", explica Correia, que adiantou o reforço de pessoal em delegacias da zona Norte, através de remanejamento, para o próximo mês de junho. (Tribuna do Norte, 30/05/2017)

(15) A partir da determinação de Ricardo Motta, contando com a ajuda de outros servidores do setor financeiro, deu-se o início à sangria dos cofres do Idema com a criação de uma conta secreta que irrigava o esquema que resultou no desvio de, pelo menos, R\$ 19 milhões. (Tribuna do Norte, 24/05/2017)

(16) O TJ Saúde atenderá a tudo que diga respeito à saúde pública. Por enquanto, apenas os casos que ainda não se transformaram em processos judiciais. Os casos de disputa com planos de saúde não fazem parte do perfil do programa. (Tribuna do Norte, $31 / 05 / 2017)$

Os dados indicam, portanto, uma tendência inversa entre restritivas e explicativas: as primeiras não ocorrem com SN de definitude máxima e são mais frequentes com nomes de especificação mínima; as explicativas seguem direção oposta, pois não foram identificadas junto a SN com mínima definitude e aumentam a ocorrência à proporção que se eleva a especificidade desse SN. O grau mediano de definitude parece não favorecer um ou outro tipo de relativa.

Esses achados se coadunam com as funções semântico-pragmáticas associadas a essas orações e confirmam nossa hipótese de trabalho. As restritivas atuam no recorte referencial do $\mathrm{SN}$ antecedente, daí vincular-se a nomes com menor grau de definitude, os quais designam entidades mais genéricas. Já as explicativas trazem informação complementar acerca do SN antecedente, funcionando como um comentário pertinente aos propósitos comunicativos do texto em que ocorrem, por isso se ligam a nomes com maior especificação.

\section{Integração semântico-sintática das relativas}

Para a análise do nível de integração entre as relativas e a oração matriz, tomamos por base os critérios propostos por Oliveira (2001): informatividade do SN antecedente, fundidade da relativa, pausa e inserção. Aplicando esses parâmetros a todas as relativas, assinalando positiva ou negativamente para cada critério, chegamos aos resultados quantitativos dispostos na Tabela 3.

\begin{tabular}{|c|c|c|c|c|c|c|}
\hline \multirow[b]{2}{*}{ Parâmetros } & \multicolumn{2}{|c|}{+} & \multicolumn{2}{|c|}{ - } & \multicolumn{2}{|c|}{ Total } \\
\hline & $\mathrm{N}^{\mathrm{o}}$ & $\%$ & $\mathrm{~N}^{\mathrm{O}}$ & $\%$ & $\mathrm{~N}^{\mathrm{o}}$ & $\%$ \\
\hline $\begin{array}{l}\text { Informatividade do SN } \\
\text { antecedente }\end{array}$ & 101 & $59 \%$ & 70 & $41 \%$ & \multirow{4}{*}{171} & \multirow{4}{*}{$100 \%$} \\
\hline $\begin{array}{l}\text { Fundidade do conteúdo } \\
\text { da oração relativa }\end{array}$ & 73 & $42,7 \%$ & 98 & $57,3 \%$ & & \\
\hline Pausa & 82 & $49 \%$ & 89 & $52 \%$ & & \\
\hline Inserção & 20 & $11,6 \%$ & 151 & $83 \%$ & & \\
\hline
\end{tabular}

De acordo com os dados constantes da tabela, a maioria dos antecedentes (59\%) apresentam mais informatividade, daí o maior percentual de relativas com conteúdo de fundo $(57 \%)$, visto que esses parâmetros se correlacionam de forma inversa: quanto mais informativo for o SN antecedente, mais caráter de fundo terá a oração relativa. Esses dados, a nosso ver, relacionam-se a características dos gêneros textuais aqui considerados (notícia e reportagem), em que as informações devem ser o mais precisas possível. Quanto à pausa, houve uma distribuição 
equilibrada das orações aqui analisadas. Já em termos de inserção, aferimos baixa quantidade de relativas com esse parâmetro $(11,6 \%)$.

Segundo destaca Oliveira (2001), a marcação positiva desses parâmetros concorre para a menor integração semântica e sintática da relativa com a oração matriz. Dito isso e considerando que as orações analisadas apresentam marcações positivas/negativas em diferentes quantidades, propusemos a seguinte escala de integração oracional das relativas: integração mínima (4 negativas), integração baixa (3 negativas), integração média (2 negativas, 2 positivas), integração alta (3 positivas) e integração máxima (4 positivas). A Tabela 4 resume, numericamente, a distribuição das relativas do corpus.

\begin{tabular}{|c|c|c|c|c|c|c|c|c|c|c|c|}
\hline \multicolumn{2}{|c|}{$\begin{array}{c}\text { Integração } \\
\text { mínima }\end{array}$} & \multicolumn{2}{|c|}{ Integração baixa } & \multicolumn{2}{|c|}{ Integração média } & \multicolumn{2}{|c|}{ Integração alta } & \multicolumn{2}{|c|}{$\begin{array}{l}\text { Integração } \\
\text { máxima }\end{array}$} & \multicolumn{2}{|c|}{ Total } \\
\hline $\mathrm{N}^{\mathrm{o}}$ & $\%$ & $\mathrm{~N}^{\mathrm{o}}$ & $\%$ & $\mathrm{~N}^{\circ}$ & $\%$ & $\mathrm{~N}^{\mathrm{o}}$ & $\%$ & $\mathrm{~N}^{\mathrm{o}}$ & $\%$ & $\mathrm{~N}^{\mathrm{o}}$ & $\%$ \\
\hline 12 & $7 \%$ & 58 & $34 \%$ & 20 & $11,7 \%$ & 30 & $17,5 \%$ & 51 & $30 \%$ & 171 & $100 \%$ \\
\hline
\end{tabular}

A distribuição escalar das relativas, conforme os parâmetros semântico-sintáticos considerados, revela nuances não capturadas pela oposição dicotômica restritivas vs explicativas. A aplicação desses parâmetros demonstra que esses dois tipos oracionais cumprem propósitos diferentes e que a distinção entre eles se manifesta em vários níveis de vinculação. As orações com graus mínimo e baixo de integração correspondem a $41 \%$ das relativas do corpus, proporção similar à quantidade de explicativas, que é de $42,7 \%$. Já as orações com maior grau de integração (alto e máximo) representam maioria $(47,5 \%)$, como é o caso das restritivas, também maioria no corpus $(57,3 \%)$. No nível intermediário de integração, foram identificadas 20 orações $(11,7 \%)$, as quais reúnem características tanto de relativa restritiva quanto de relativa explicativa. Vejamos as amostras (7), (14) e (16), retomadas a seguir, e a ocorrência em (17):

(7) Nesta quarta-feira (28), a Câmara de Natal aprovou em segunda discussão o Projeto de Lei $\mathbf{n}^{\circ}$ 40/2017, de autoria do presidente da Casa, vereador Raniere Barbosa (PDT), que cria a Lei Karol Álvares, instituindo o dia 20 de janeiro como o Dia Municipal das Mães que sofrem da Síndrome dos Braços Vazios, em razão da violência urbana. A iniciativa recebeu parecer favorável de todos os parlamentares presentes no plenário. (Tribuna do Norte, 29/06/2017)

(14) "Estamos com a Divisão de Homicídios e Proteção a Pessoa (DHPP) reforçada, com mais viaturas e policiais. Remanejamos policiais de outras unidades dentro do estudo de mancha criminal, onde há maior necessidade de investigação, para darmos maior andamento aos trabalhos", explica Correia, que adiantou o reforço de pessoal em delegacias da zona Norte, através de remanejamento, para o próximo mês de junho. (Tribuna do Norte, 30/05/2017)

(16) O TJ Saúde atenderá a tudo que diga respeito à saúde pública. Por enquanto, apenas os casos que ainda não se transformaram em processos judiciais. Os casos de disputa com planos de saúde não fazem parte do perfil do programa. (Tribuna do Norte, 31/05/2017)

(17) Enquanto não houver decisão judicial relativa ao caso, as obras às margens das rodovias ficarão prejudicadas. Existem, porém, outros gargalos que, caso não sejam solucionados num curto intervalo de tempo, poderão atrapalhar o andamento de obras importantes. (Tribuna do Norte, 27/05/2017)

Embora sejam tomadas, conforme a classificação tradicional, como tipos discretos de relativas, no caso, explicativas em (7) e (14), e restritivas em (16) e (17), essas orações exibem 
graus diferentes de integração de forma e de conteúdo em relação à matriz. Considerando os parâmetros semântico-sintáticos anteriormente elencados, (7) mostra-se positiva para informatividade, fundidade, inserção e pausa, exibindo grau mínimo de integração, ao passo que (14) tem marcação negativa para inserção, apresentando grau baixo de vinculação. A relativa em (16), por sua vez, exibe grau máximo de integração, sendo marcada negativamente para todos os parâmetros, enquanto, em (17), a oração sublinhada apresenta marcação positiva para fundidade e inserção, e negativa para informatividade e pausa, exibindo grau médio de integração.

Vistas sob essa perspectiva, as orações relativas exibem gradiência categorial, no sentido de que há aquelas com grau máximo de integração semântico-sintática à oração matriz, constituindo as restritivas prototípicas e, no outro extremo, as relativas com mínima integração com a matriz, representando as explicativas exemplares. Entre esses extremos situam-se, de forma escalar, as relativas com grau alto, médio e baixo de integração, com propriedades que ora as aproximam das restritivas, ora das explicativas.

Esse continum de integração está diretamente relacionado aos modos de combinação oracional, que vão da parataxe à subordinação, passando pela hipotaxe, conforme o cline proposto por Hopper e Traugott (1993). Assim, a gradiência revelada pela análise das relativas de nossa amostra indica que as explicativas prototípicas exibem propriedades que as situam na hipotaxe e/ou na parataxe, devido à relação mais frouxa e/ou de adjunção com a oração matriz. As restritivas típicas, por sua vez, dada a maior vinculação à matriz, relacionam-se por encaixamento, sendo, portanto, subordinadas.

\section{CONSIDERAÇÕES FINAIS}

Sob as lentes da Linguística Funcional norte-americana, focalizamos as relações de explicação e restrição, comumente associadas às orações relativas, analisando tais orações em perspectiva escalar. Para tanto, consideramos propriedades formais e semântico-pragmáticas dos $\mathrm{SN}$ antecedentes e as correlacionamos ao tipo de relativa que a eles se vincula. Propusemos um continuum de integração oracional para as relativas do corpus com base em critérios semânticosintáticos sugeridos por Oliveira (2001).

Constatamos que SN mais genéricos, com baixo grau de especificidade e novos no discurso ligam-se, com maior frequência, a orações restritivas. Isso porque essas orações atuam no recorte referencial da entidade designada pelo $\mathrm{SN}$ antecedente, cumprindo o objetivo comunicativo de circunscrever, com mais precisão para o interlocutor, o elemento a que o falante remete. As explicativas, por sua vez, vinculam-se, mais frequentemente, a SN disponíveis e com maior grau de definitude, funcionando como um comentário pertinente, em termos de justificativa, esclarecimento, para os propósitos do texto em que ocorrem. Já os antecedentes evocados e inferíveis ocorrem com ambos os tipos de relativas.

Em termos de articulação com a oração matriz, verificamos que a relativa exibe diferentes graus de integração, daí elaboramos um continum que captura esses variados níveis. Com essa proposta, pudemos analisar melhor a gradiência percebida entre as várias orações do corpus e constatar que, a despeito da categorização dicotômica restritiva vs explicativa, encontramos, no uso efetivo da língua, relativas que se situam em pontos distintos de uma escala que vai da explicação, em um extremo, à restrição, em outro, com trechos intermediários. Esse continnum tem respaldo no cline de Hopper e Traugott (1993), corroborando nossa defesa de que explicativas típicas articulam-se à oração matriz por hipotaxe, ao passo que as restritivas prototípicas o fazem por subordinação. 


\section{REFERÊNCIAS}

AMORIM, Monika Benttenmüller. Orações adjetivas não prototípicas do português: relações discursivas e gramaticais. Tese (Doutorado em Estudos de Linguagem). Universidade Federal Fluminense, Niterói, 2011.

BISPO, Edvaldo Balduino. Oração adjetiva cortadora: análise de ocorrências e implicações para o ensino de português. Linguagem \& Ensino, v. 10, n. 1, p. 163-186, 2007.

BISPO, Edvaldo Balduíno. Estratégias de relativização no português brasileiro e implicações para o ensino: o caso das cortadoras. Tese (Doutorado em Estudos da Linguagem) - Programa de Pós-Graduação em Estudos da Linguagem, Universidade Federal do Rio Grande do Norte, Natal, 2009.

BISPO, Edvaldo Balduíno. Estratégias de relativização no PB: motivações discursivointeracionais e cognitivas. In: BISPO, Edvaldo Balduíno; OLIVEIRA, Mariangela Rios de. Orações relativas no português brasileiro: diferentes perspectivas. Niterói: EdUFF, 2014a, p. 131-155.

BISPO, Edvaldo Balduíno. Orações relativas em perspectiva histórica: interface uso e cognição. Veredas, v. 18, n. 1, p. 222-235, 2014b.

BISPO, Edvaldo Balduíno. Relativa restritiva em perspectiva construcional. Entrepalavras, Fortaleza, v. 8, n. Especial, p. 28-44, 2018.

BISPO, Edvaldo Balduíno. Quem cala consente: abordagem funcional-construcionista de relativas sem antecedente introduzidas por quem'. Gragoatá, Niterói, v. 25, n. 52, p. 601-626, 2020.

BISPO, Edvaldo Balduíno; AMURIM, Maria Estela Lima Costa de. Articulação oracional e produção escrita: um trabalho com o pronome relativo. Investigações (online), Recife, v. 32, p. 275-304, 2019.

BISPO, Edvaldo Balduíno; SILVA, Lígia Maria. Abordagem funcionalista da oração adjetiva: uma intervenção pedagógica no ensino fundamental. Entrepalavras, Fortaleza, v. 10, p. 1-21, 2020.

BISPO, Edvaldo Balduíno; BRAGA, Aline Priscilla de Albuquerque. Propriedades funcionais da relativa livre introduzida por 'quem'. Revista Soletras, Rio de Janeiro, v. 41, p. 265-289, 2021.

BRITO, Ana Maria Barros de. A sintaxe das orações relativas em português. Tese (Doutorado em Linguística Portuguesa). Universidade do Porto, Portugal, 1988.

CÂMARA, Aliana Lopes. A oração relativa em português: interface entre a descrição e o ensino. Tese (Doutorado em Estudos Linguísticos). Universidade Estadual Paulista Júlio de Mesquita Filho, São José do Rio Preto, 2015.

CASTILHO, Ataliba Teixeira de. Nova gramática do português brasileiro. São Paulo: Contexto, 2010.

CHAFE, Wallace. Significado e estrutura linguística. Tradução de Maria Helena de Moura Neves, Odette Gertrudes Luíza Altmann de Souza Campos, Sônia Veasey Rodrigues. Rio de Janeiro: Livros Técnicos e Científicos, 1979.

CODINHOTO, Gabriela Maria de Oliveira. A acessibilidade das construções relativas e a aquisição da escrita. Tese (Doutorado em Estudos Linguísticos). Instituto de Biociências, Letras e Ciências Exatas, Universidade Estadual Paulista (UNESP), São José do Rio Preto, 2016. 
CORREA, Vilma Reche. Oração relativa: o que se fala e o que se aprende no português do Brasil. Tese (Doutorado em Linguística). Universidade Estadual de Campinas, Campinas-SP, 1998.

DECAT, Maria Beatriz Nascimento. Por uma abordagem de (in)dependência de cláusulas à luz da noção de "unidade informacional". Scripta, v. 2, n. 4, p. 23-38, 1999.

DECAT, Maria Beatriz Nascimento. Estruturas desgarradas em língua portuguesa. Campinas: Pontes, 2011.

DU BOIS, John W. Competing motivations. In: HAIMAN, J (ed). Iconicity in sintax. Amsterdam: John Benjamins, 1985, p. 343-365.

FIORATTI, Carolina. A maioria de espécies de tubarão de mar aberto podem ser extintas. Superinteressante, 2021. Disponível em: https://super.abril.com.br/ciencia/a-maioria-dasespecies-de-tubarao-de-mar-aberto-podem-ser-extintas/. Acesso em: 28 jan. 2021.

FURTADO DA CUNHA, Maria Angélica; BISPO, Edvaldo Balduíno. Pressupostos teóricometodológicos e categorias analíticas da Linguística Funcional Centrada no Uso. Revista do GELNE. v. 15, n. 1/2, p. 53-78, 2013.

GIVÓN, Talmy. On understanding grammar. New York: Academic Press, 1979.

GIVÓN, Talmy. Syntax: a functional-typological introduction. Amsterdam: John Benjamins, 1984.

GIVÓN, Talmy. Functionalism and grammar. Amsterdam: John Benjamins, 1995.

GÖRSKI, Edair. Condições de entrada e de continuidade do referente em narrativas orais. Dissertação (Mestrado em Linguística), Universidade Federal do Rio de Janeiro, Rio de Janeiro, 1985.

HOPPER, Paul; TRAUGOTT, Elizabeth Closs. Grammaticalization. Cambridge: Cambridge University Press, 1993.

KENEDY, Eduardo. A antinaturalidde de pied-piping em orações relativas. Rio de Janeiro, Tese (Doutorado em Linguística). Universidade Federal do Rio de Janeiro, Rio de Janeiro, 2007.

LAKATOS, Eva Maria; MARCONI, Marina de Andrade. Fundamentos da metodologia científica. In: Fundamentos da metodologia científica. 2010. p. 320-320.

LEITÃO, Renata Borges. Relativas explicativas: aspectos sintático-semânticos e textualdiscursivos. Tese (Doutorado em Linguística), Universidade Federal do Ceará, Fortaleza, 2009.

LOPES, Anielle Bruna Fonseca. O papel das orações adjetivas na ancoragem de referentes nominais. Dissertação (Mestrado em Estudos da Linguagem), Universidade Federal do Rio Grande do Norte, Natal, 2019.

MARCHESAN, Ani Carla. As Relativas Livres no Português Brasileiro. Florianópolis, Tese (Doutorado em Linguística). Universidade Federal de Santa Catarina, Florianópolis, 2012.

MARCUSCHI, Luiz Antônio. Gêneros textuais: definição e funcionalidade. In: DIONÍSIO, Angela Paiva; MACHADO, Anna Rachel; BEZERRA, Maria Auxiliadora. Gêneros textuais e ensino. 4. ed. Rio de Janeiro: Lucerna, 2005, p. 19-36.

MARCUSCHI, Luiz Antônio. Produção textual, análise de gêneros e compreensão. São Paulo: Parábola, 2008 
MARTELOTTA, Mário Eduardo. Mudança linguística: uma abordagem centrada no uso. São Paulo: Cortez, 2011.

MOLLICA, Maria Cecília de Magalhães. O estudo da cópia nas construções relativas em português. Dissertação (Mestrado em Letras), Pontifícia Universidade Católica, Rio de Janeiro, 1977.

NUNES, Marcos. Universitário preso com drogas sintéticas planejava vender material em festa rave, diz polícia. Extra, 2021. Disponível em: https://extra.globo.com/casos-depolicia/universitario-preso-com-drogas-sinteticas-planejava-vender-material-em-festa-rave-dizpolicia-24857346.html. Acesso em: 28 jan. 2021.

OLIVEIRA, Mariangela Rios de. Orações adjetivas: uma abordagem funcional. In: PASSEGGI, Luís Álvaro Sgadari; OLIVEIRA, Maria do Socorro (Orgs.). Linguística e educação: gramática, discurso e ensino. São Paulo: Terceira Margem, 2001, p. 77-90.

PERRONI, Maria Cecília. As relativas que são fáceis na aquisição do português brasileiro. DELTA, São Paulo, v. 17, n. 1, p. 59-79, 2001.

PRINCE, Ellen F. Toward a taxonomy of given/ new information. In: COLE, Peter. (Ed.). Radical Pragmatics, New York: Academic Press, 1981, p. 223-254.

RODRIGUES, Violeta Virgínia. Articulação de orações: pesquisa e ensino. Rio de Janeiro: EDUFRJ, 2010.

SILVA, Cassandra Ribeiro de Oliveira. Metodologia e organização do projeto de pesquisa (Guia prático). Fortaleza-CE: Centro Federal de Educação Tecnológica do Ceará, 2004.

SILVA, Lígia Maria. Abordagem funcionalista da oração adjetiva: descrição e ensino. Tese (Doutorado em Estudos da Linguagem). Universidade Federal do Rio Grande do Norte, Natal, 2020.

SOUZA, Elenice S. de Assis Costa de. A interpretação das cláusulas relativas no português do Brasil: um estudo funcional. Tese (Doutorado em Língua Portuguesa), Faculdade de Letras. Universidade Federal do Rio de Janeiro, Rio de Janeiro, 2009.

TARALLO, Fernando Luiz. Relativization Strategies in Brazilian Portuguese. Tese (Doutorado em Filosofia), University of Pennsylvania, Philadelphia, 1983.

VAREJÃO, Filomena de Oliveira Azevedo. Variação das estratégias de concordância verbal e em estratégias de relativização no português europeu popular. Tese (Doutorado em Linguística). Universidade Federal do Rio de Janeiro, Rio de Janeiro, 2006.

Submetido em 22/04/2021

Aceito em 12/07/2021 